\title{
31. PHYSICAL PROPERTIES OF CALCAREOUS SEDIMENTS FROM THE SOUTHWEST PACIFIC ${ }^{1}$
}

\author{
Roger H. Morin, Massachusetts Institute of Technology, Cambridge ${ }^{2}$
}

\begin{abstract}
The extensive hydraulic piston coring activity on Leg 90 provided hundreds of meters of good quality sediment from which to conduct a comprehensive physical properties examination of nannofossil ooze and chalk. Most sites exhibit a well-defined transitional zone between the soft ooze and the indurated chalk, and a clear correlation is established between the onset of this region and sharp increases in sediment shear strength. Distinct increases in the values of compressional velocity and thermal conductivity across the ooze-to-chalk transformation are less evident. In a few instances, the porosity-versus-depth profiles depict zones where sediment porosity remains relatively constant across substantial depth intervals. Porosity is seemingly unaffected by large increases in overburden pressure, and no significant compaction occurs across several hundred meters of the sediment column. This behavior is attributed to a combination of several environmental factors. It is postulated that remarkably high sedimentation rates, a high diagenetic potential, and, perhaps, an appropriate grain size distribution all have had some relative influence in promoting sediment rigidity and retarding compaction.
\end{abstract}

\section{INTRODUCTION}

Leg 90 was principally organized as a paleoenvironmental expedition, with an ambitious and extensive program of hydraulic piston coring scheduled at eight sites traversing tropical to subantarctic areas of the southwest Pacific. Over the last few years, the hydraulic piston corer (HPC) has demonstrated the ability to recover highquality geologic samples to depths of several hundred meters into the seafloor; this tool was utilized once again for the high-resolution paleoceanographic studies proposed for the region. Several thousand meters of relatively undisturbed core were retrieved by the HPC, and these provided a valuable opportunity to examine sediment physical properties in light of the depositional and lithification processes that occur in the ocean basins.

A comprehensive physical properties program was initiated during the course of the cruise, and a vast quantity of scientific data was generated. The shipboard experiments included the Gamma Ray Attenuation Porosity Evaluator (GRAPE) (Boyce, 1976b); gravimetric determination of wet-bulk density, grain density, and porosity (Boyce, 1976b); estimation of thermal conductivity (Chaney et al., 1983); measurement of compressional wave acoustic velocity (Boyce, 1976a); and evaluation of sediment shear strength (Boyce, 1976a).

Most of these experimental results have been presented in the individual site chapters of this volume, and detailed descriptions of the laboratory equipment and methodology are contained in the introductory chapter. This chapter attempts to correlate and compare data from various sites, and focuses upon the physical characteristics of calcareous sediments only. For all of the sites except Site 594, $\mathrm{CaCO}_{3}$ content remained high, consistent-

\footnotetext{
${ }^{1}$ Kennett, J. P., von der Borch, C. C., et al., Init. Repts. DSDP, 90: Washington (U.S. Govt, Printing Office).

2 (Present address): U.S. Geological Survey, Denver, CO 80225.
}

ly above $90 \%$, and physical properties profiles versus depth share the same trends (Sites 587, 588, 590, 591, $592,593)$. These sites consisted almost exclusively of nannofossil ooze (grading into chalk) and/or foraminiferbearing nannofossil ooze (grading into chalk) with occasional trace amounts of siliceous material, such as radiolarians, sponge spicules, and volcanic glass. Sediments at Site 594 contained numerous intervals of terrigenous material, such as clayey silt, and data from this final hole are not included in this review.

\section{GRAPE ANALYSES}

The Gamma Ray Attenuation Porosity Evaluator was used in a continuous scanning mode in order to estimate sediment wet-bulk density. Boyce (1976b) describes the instrument and operational procedure in detail and considers the sources of error associated with the measurement. These include liner variation, integrity of the geologic material, and change in gamma-ray path length. The greatest problem in reliability of the data has arisen where hard rocks or indurated sediments have not completely filled the core liners. In these cases, geometric concerns caused by a shorter gamma-ray path length through the geologic sample have made the values of wet-bulk density suspect.

During HPC deployment in soft sediments, the liner was completely filled with relatively undisturbed materi$\mathrm{al}$, and no geometric adjustments to the GRAPE data were required. Mayer (1982) has addressed the issue of sediment disturbance and has found specimen quality to be very high when the HPC has functioned properly. HPC refusal began to occur during this cruise at coring depths near $250 \mathrm{~m}$, coincident with the appearance of the stiffer chalks, and a newly developed extended core barrel (XCB) was utilized for subsequent core retrieval. Site 590 represented the first successful deployment of the XCB. Cores obtained with this apparatus were slightly to moderately disturbed, often consisting of biscuits 
of indurated sediments surrounded by an annular slurry of soft ooze injected during the coring process. This soft material is expected to cause GRAPE wet-bulk density estimates to be slightly less than the actual values; a 3 mm-thick slurry wall adjacent to the $6.61-\mathrm{cm}$ inside diameter of the core liner should decrease the average density by 1 to $2 \%$. Gravimetric analyses of chunk samples (Boyce, 1976b) taken from these deep cores, however, yielded wet-bulk density results that were in very good agreement with the uncorrected GRAPE-generated data. Thus, the GRAPE results presented in this chapter, measured on both the HPC and the XCB cores, have not been adjusted for possible geometric errors.

The porosity-versus-depth profiles displayed in Figure 1 were derived from the GRAPE saturated wet-bulk density data. Carbonate content is one parameter that directly controls porosity and density; it was uniformly high throughout the sediment columns at all pertinent sites. The grain density of biogenic calcite is $2.72 \mathrm{~g} / \mathrm{cm}^{3}$, whereas that of silica is 2.1 to $2.3 \mathrm{~g} / \mathrm{cm}^{3}$ (Baas Becking and Moore, 1959). An average grain density was assumed to be $2.69 \mathrm{~g} / \mathrm{cm}^{3}$, and the saturated wet-bulk density results were accordingly converted to values of sediment porosity.

In this situation of constant grain density, porosity essentially mirrors the bulk density profile. The dashed lines in Figure 1 identify the individual depths where an ooze-to-chalk transition was observed. The corresponding transitional porosities range from approximately 50 to $53 \%$. Hole 592 contains two separate transitional appearances. An initial onset of chalk is observed at $260 \mathrm{~m}$, followed by a reintroduction of calcareous ooze. This sequence quickly undergoes a transition to chalk again at a depth of approximately $330 \mathrm{~m}$. The gap in porosity data for Site $593(360-500 \mathrm{~m})$ was caused by a GRAPE instrument malfunction that was not detected immediately.

The effective overburden pressure at each site was computed from the GRAPE wet-bulk density data averaged across the incremental depth intervals, assuming no excess pore pressures. Plots of cumulative effective stress versus depth are presented in Figure 2, again with the dashed horizontal lines representing the ooze-to-chalk transitional levels. By comparing Figures 1 and 2, it is interesting to note the instances where little or no obvious consolidation has occurred across substantial depth intervals, even with significant, systematic increases in lithostatic load. At Site 590, for example, average porosity remains effectively constant, apart from high frequency fluctuations, across a $250-\mathrm{m}$ span of the sediment column $(200-450 \mathrm{~m})$. Similar behavior is observed, but to a lesser extent, at Sites 591 and 592. At Site 593, porosity is shown to decrease through the upper $50 \mathrm{~m}$, but to remain relatively constant over the next $300 \mathrm{~m}$ as sediment overburden pressure is gradually increased from approximately 4 to $26 \mathrm{~kg} / \mathrm{cm}^{2}$.

\section{THERMAL CONDUCTIVITY}

Sediment thermal conductivity was measured through the core liner at Sites 587 and 588 utilizing the needle probe method (Chaney et al., 1983); the results are plotted versus depth in Figure 3. These data were obtained aboard ship and have not been corrected for in situ pressure and temperature conditions. Morin and Von Herzen (this volume) have performed this exercise at selected depths in order to compute oceanic heat flow and report a total correction of only $2.6 \%$. The experimental error in this particular case is approximately $\pm 4 \%$.

The thermal conductivity values were cross correlated with the porosity profiles of Sites 587 and 588 in order to arrive at a relationship between conductivity and porosity for calcareous sediments (Fig. 4). Numerous models designed to provide a suitable estimate for the thermal conductivity of two-phase media with static liquid component have been proposed (Wyllie and Southwick, 1954; Jeffrey, 1973; Crane and Vachon, 1977). A detailed solution of this conduction problem, however, requires that the shape, size, location, and conductivity of each particle be known. Analytical models have attempted to overcome this difficulty in describing the microstructure by proposing a number of simplifying assumptions.

Ohm's Law models, for instance, are designed to represent randomly packed granular systems by equivalent electrical analogs. Broad constraints are placed on the bulk thermal conductivity of the system by considering two different phase networks. The series and the parallel arrangements correspond to the minimum and maximum possible values for conductivity, respectively. Curves $\mathrm{A}$ and $\mathrm{B}$ in Figure 4 illustrate these bounds, assuming the fluid and solid conductivities to be 0.61 and 2.85 $\mathrm{W} / \mathrm{m}-\mathrm{K}$, respectively (Clark, 1966).

If the values of the separate phase conductivities differ significantly, the established bounds are so broad as to fail to provide useful limits. Hashin and Shtrikman (1962) have shown that their exact, rigorous solution produces the narrowest possible constraints on thermal conductivity for macroscopically heterogeneous, isotropic media. Their model consists of a well-separated suspension of spheres of varying size; one phase is continuous and the other discrete. Curves C and D in Figure 4 are the conductivity bounds determined by the Hashin and Shtrikman (1962) analysis. Curve C defines the case of a dominant fluid component, with sediment grains suspended in seawater. Curve D assumes a continuous solid matrix containing individual pores. Theoretically, as a calcareous sediment gradually undergoes consolidation, the thermal conductivity data are expected to deviate from Curve C (liquid dominated-ooze) and approach curve D (solid dominated-chalk). This behavior is not clearly substantiated by the results plotted in Figure 4 . However, the narrow limits imposed by the Hashin and Shtrikman (1962) model do successfully constrain all of the individual data points.

\section{SHEAR STRENGTH}

Shear strength was measured on split cores in the original horizontal direction with a modified Wykeham Farrance laboratory vane apparatus (Boyce, 1976a). The test procedure was repeated until the sediment became so lithified that its strength exceeded the capability of the 
587

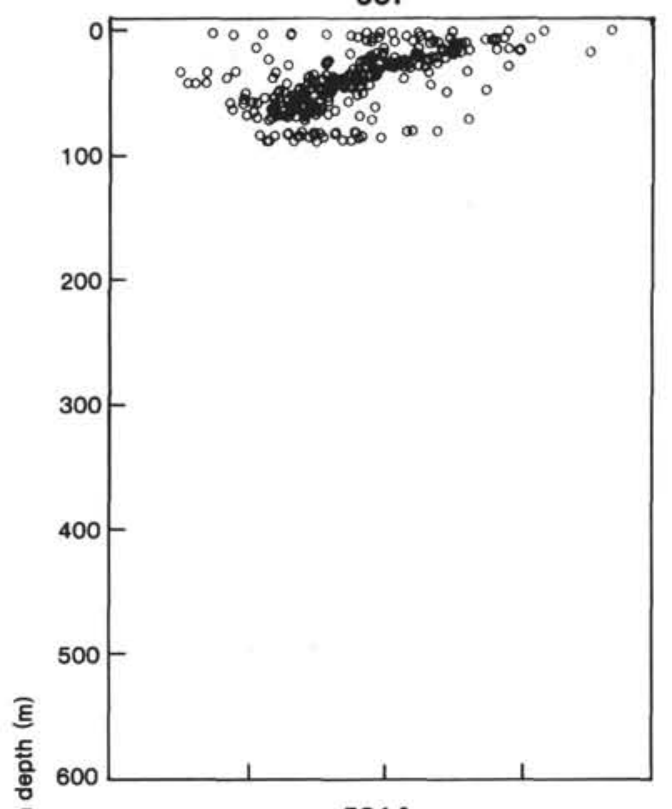

ह

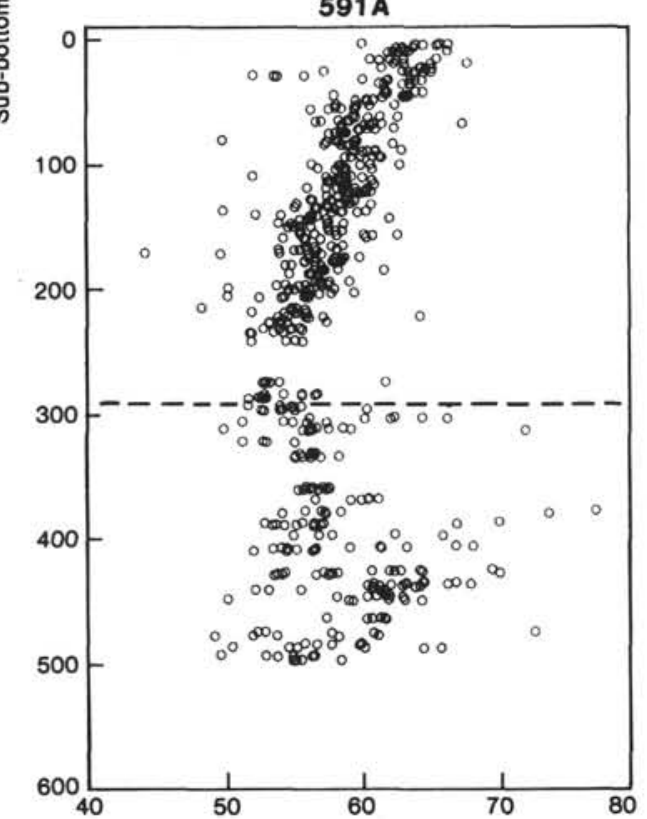

588B,C

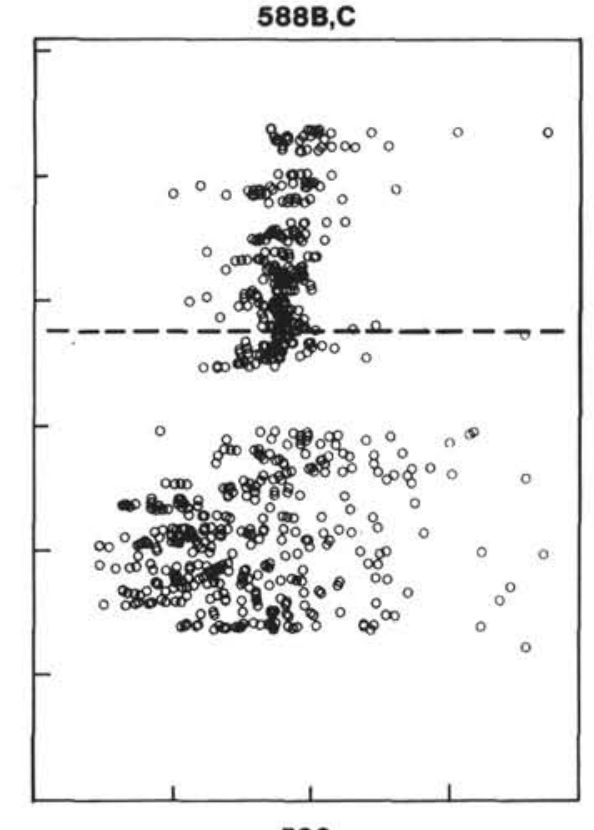

592

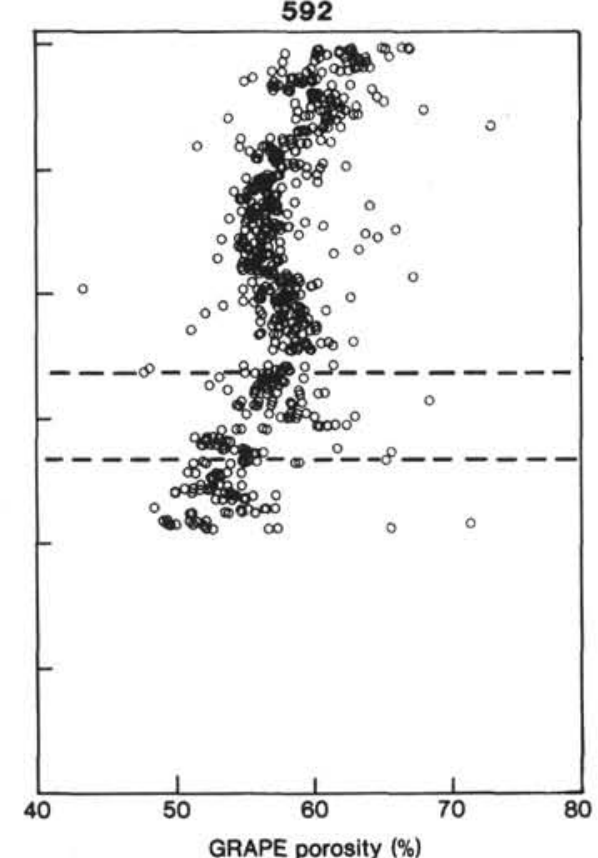

590B
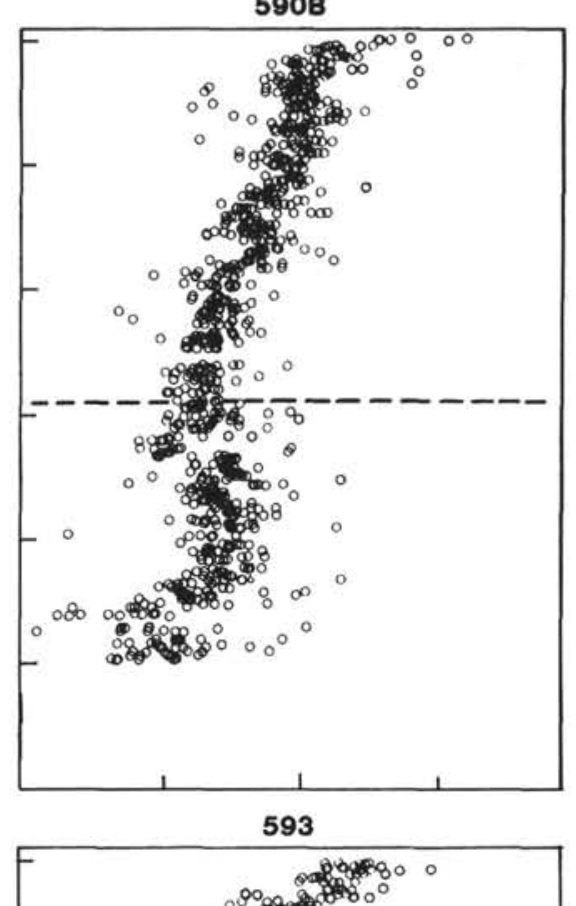

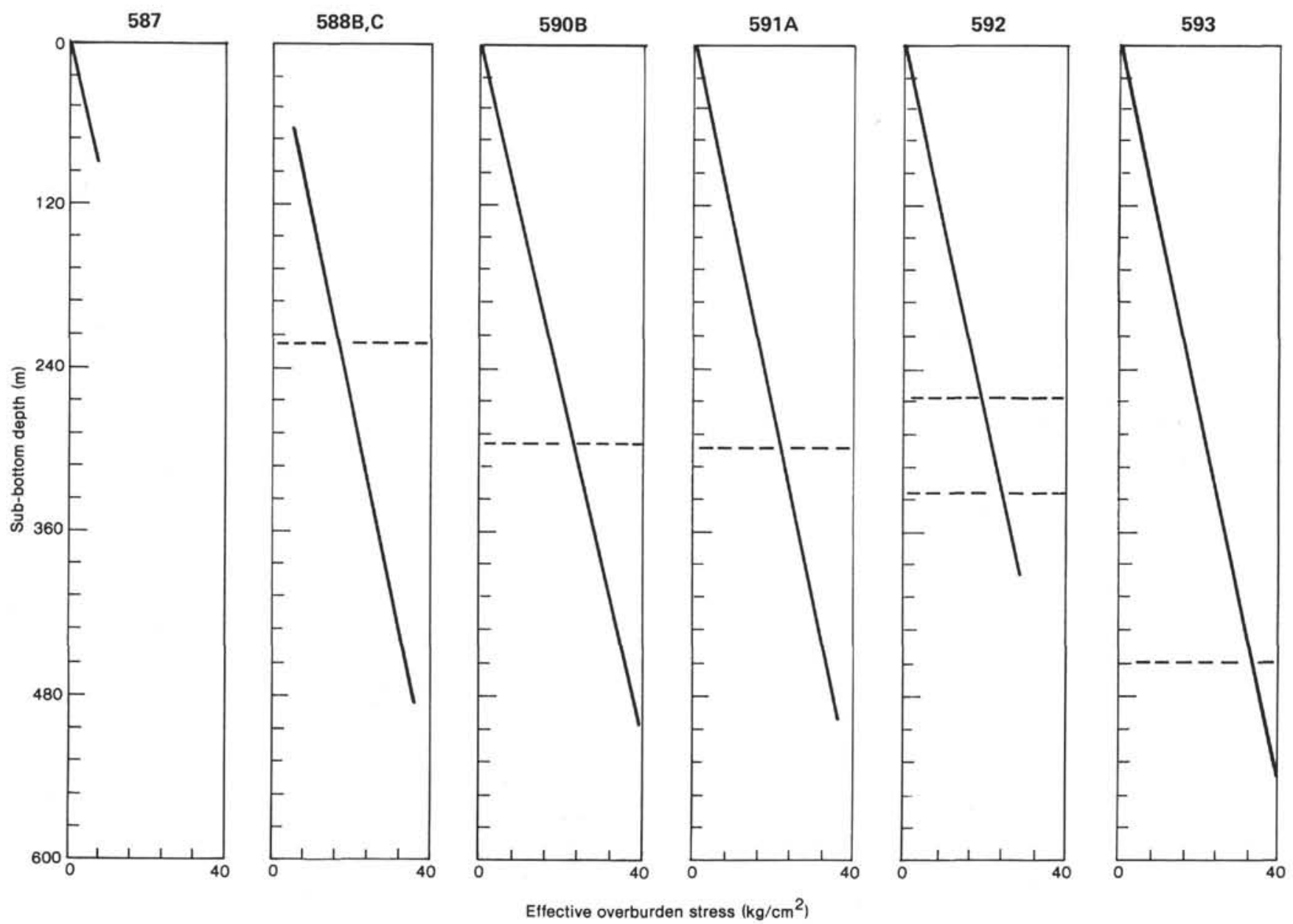

Figure 2. Multiple plot of effective overburden pressure versus depth for six sites. Dashed line indicates ooze-to-chalk transitional depth.

instrument. This condition coincided with the appearance of chalk and closely followed the retooling of coring operations from the HPC to the XCB. Results are recorded versus depth in Figure 5 for Sites 590, 591, and 592. At Site 592, where there were two transitional depths, a sizable increase in shear strength at the initial onset of chalk was followed by a gradual decline and, finally, by another sharp increase in this property at the second ooze-to-chalk transition. When these results are cross correlated with the individual site porosity profiles, a clear dependence of shear strength upon porosity is observed. This relationship is illustrated in Figure 6; the dashed line represents a least-squares polynomial fit of the data. This best-fit approximation is described by the following equation.

$$
S=40461.3-1956.7 \phi+31.60 \phi^{2}-0.170 \phi^{3}
$$

where $S=$ shear strength $\left(\mathrm{g} / \mathrm{cm}^{2}\right)$ and $\phi=$ porosity $(\%)$. A sudden increase in shear strength is observed as the porosity approaches the transitional region, estimated as being in the range of 50 to $53 \%$ for all sites considered. At porosities below the ooze-to-chalk transformation, lithification is so pronounced that the miniature vane device can no longer penetrate the sediments to produce an accurate estimate of shear strength.

\section{ACOUSTIC VELOCITY}

Sediment acoustic velocity was measured on board ship on split cores, parallel to bedding (Boyce, 1976b), and the results from four sites are plotted versus depth in Figure 7. Unlike the shear strength determination, which was limited by the range of the laboratory instrument, seismic velocity results continued to be collected below the ooze-to-chalk transformation. The data obtained from Sites 588, 590, and 592 show little change in compressional wave velocity over the top $300 \mathrm{~m}$ of the sediment column. In their physical properties study, Wilkens and Langseth (1983) report that seismic velocity exhibited the least variation with depth of any of the parameters measured; Mayer $(1979,1982)$ arrived at a similar conclusion. Fluctuations in this elastic property remained small across large depth intervals, even as other physical properties changed significantly. Small velocity increases became evident as porosities declined into the chalk region, though this shift to higher values was not nearly so pronounced as that observed with the shear strength data. The Site 591 profile shows greater variations in acoustic velocity at the lower depths because of early diagenetic alteration produced by a spectacular sedimentation rate of $131 \mathrm{~m} / \mathrm{m}$.y. during the early Pliocene. Calcareous nannofossils begin to exhibit signs of overgrowths 


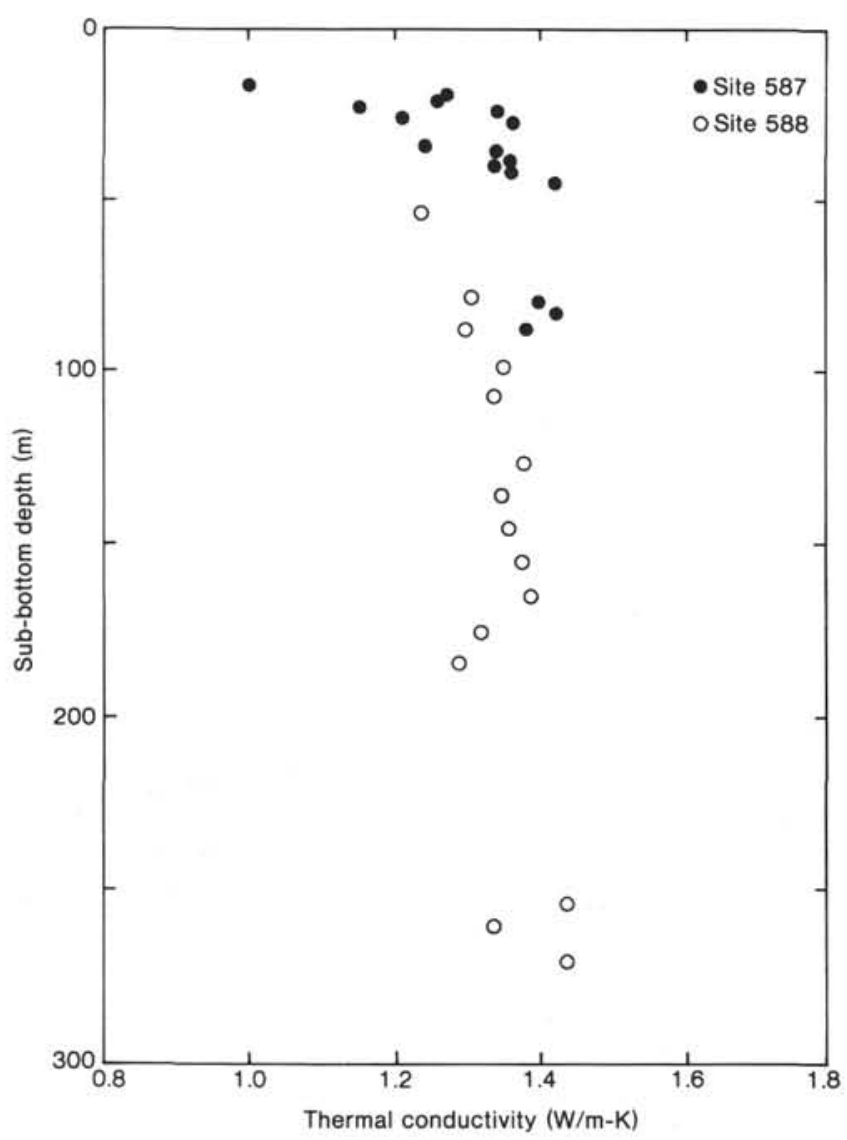

Figure 3. Plot of sediment thermal conductivity (Sites 587 and 588) versus depth. at a depth of $260 \mathrm{~m}$. These cementing agents develop sediment framework, increase matrix rigidity, and allow elastic energy to be more readily transmitted.

\section{DISCUSSION}

The set of physical properties data presented in this chapter provides a good base from which to investigate the consolidation characteristics of calcareous ooze and chalk. Coogan and Manus (1975) have presented a comprehensive review of this complex subject, with its numerous interrelated facets. They categorize the sets of conditions that directly affect the compaction of carbonates as the following: (1) inherited factors such as grain size, packing arrangement, and sorting; (2) inhibitory factors that discourage compaction, principally cementation; and (3) dynamic factors such as rate of loading, pore pressure, overburden pressure, and nature of formation fluid. It is significant to this discussion to note that if compactive stresses are high enough, deformation will occur regardless of the relative influences of any other factors. Instances are found from the profiles depicted in Figure 1 where the sediment column displayed little or no evidence of systematic lithostatic compaction, and where porosity remained essentially constant across hundreds of meters of depth. This behavior is now considered in terms of the primary factors classified previously.

Apart from Site 588, all locations experienced remarkably high sedimentation rates during the late to early Pliocene. These ranged from 57 to $131 \mathrm{~m} / \mathrm{m}$.y. and correspond to depths of approximately 40 to $200 \mathrm{~m}$. It is

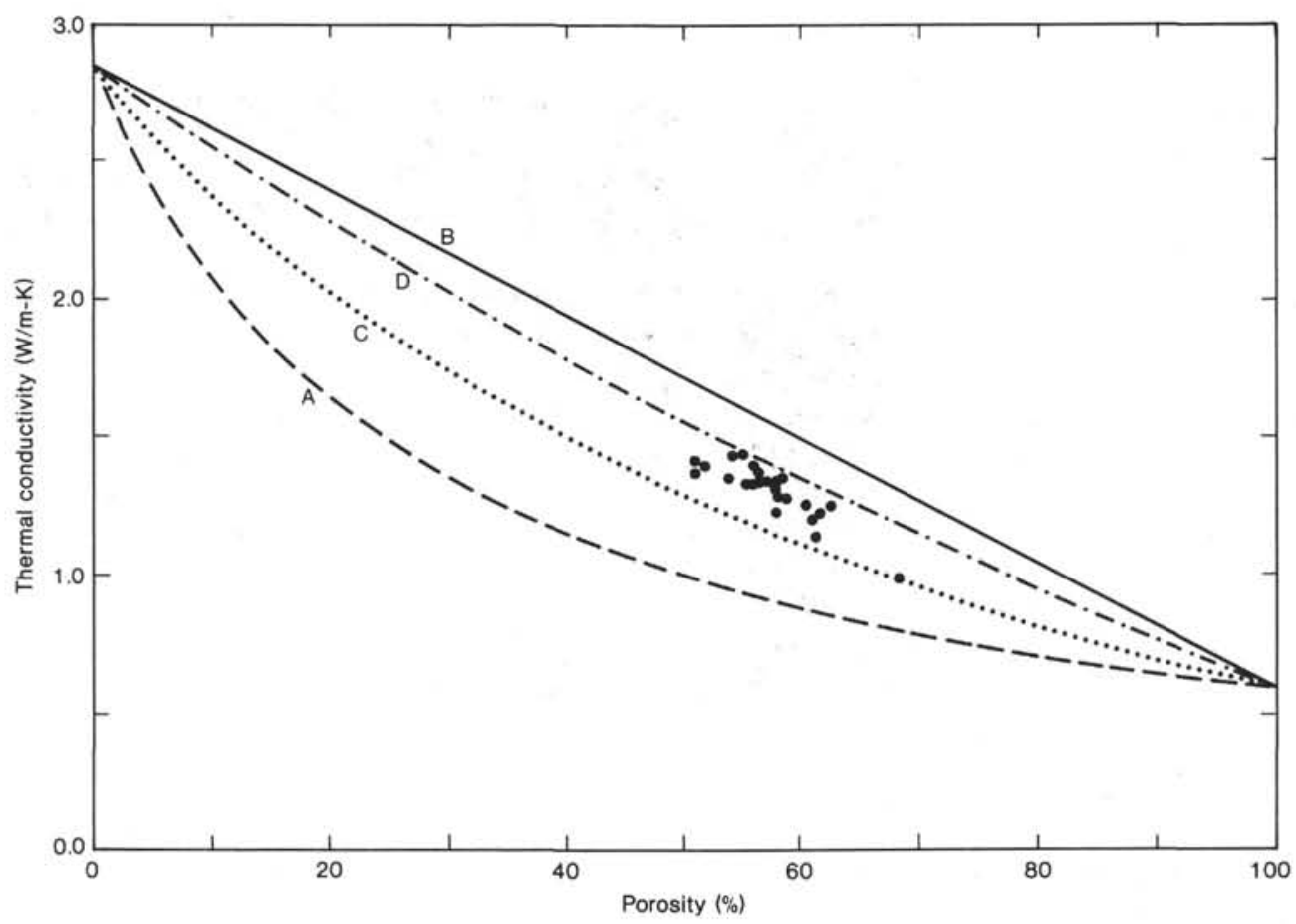

Figure 4. Plot of sediment thermal conductivity (Sites 587 and 588) versus porosity. Curves A and B are series and parallel bounds, respectively. Curves C and D are constraints defined by Hashin and Shtrikman (1962). 

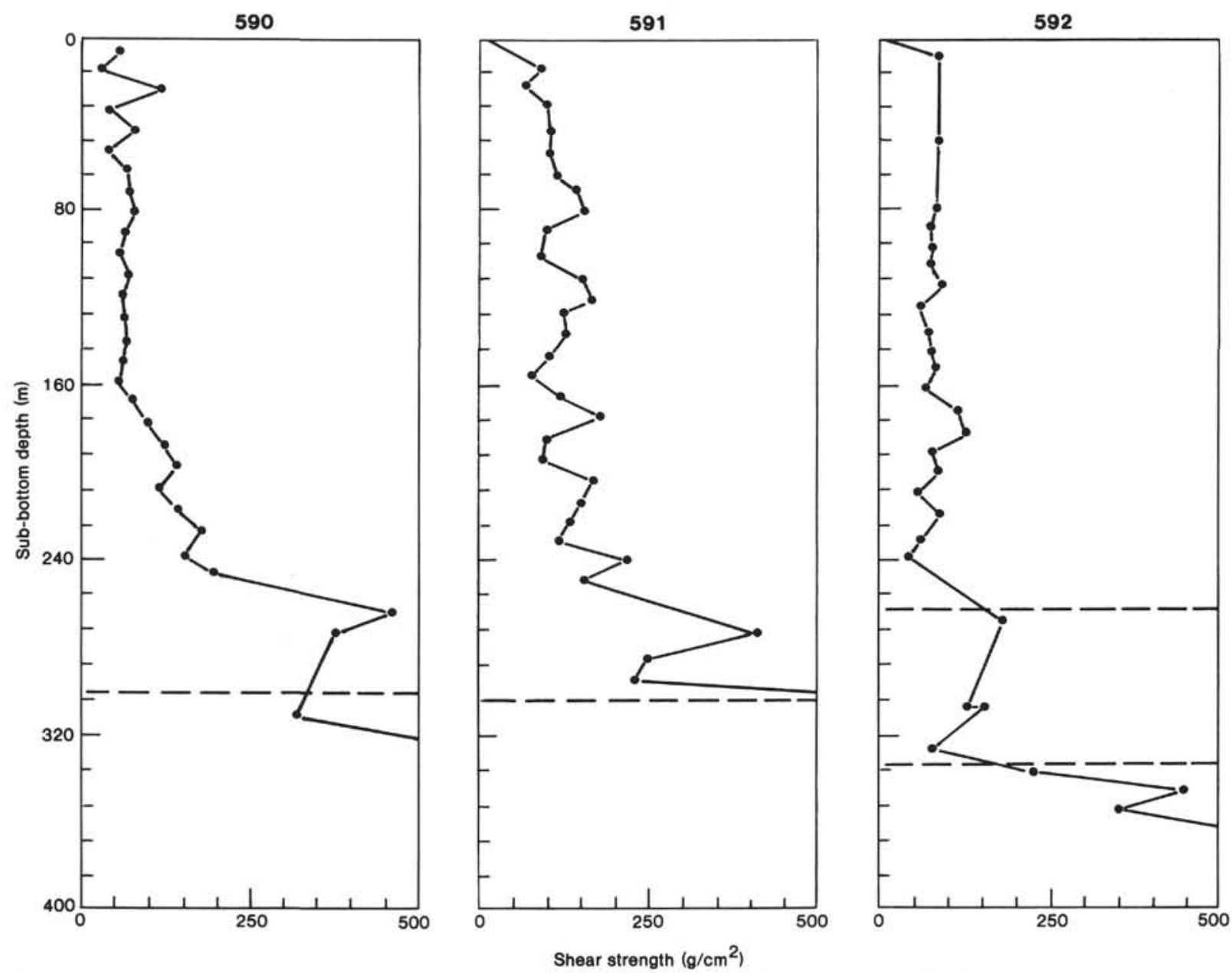

Figure 5. Multiple plot of shear strength versus depth for three sites. Dashed line indicates ooze-to-chalk transitional depth.

possible that excess pore pressures induced by these large depositional rates delayed initial consolidation, enabling the sediment particles to establish a competent, solid matrix before complete dissipation of pore pressures occurred.

The phenomenon of early lithification of carbonate sediments has been addressed by Bathurst (1971) and Schlanger (1963), among others. Weller (1959) attributes the relatively high porosities and lack of compaction in carbonate sands to early and widespread cementation. At Site 591, a premature introduction of chalk is caused by a diagenetic change in the state of fossil preservation. Schlanger and Douglas (1974) have defined the concept of diagenetic potential, whereby the variations in the degree of cementation and textural changes across oozechalk-limestone sequences are ascribed to paleoceanographic conditions or events. The ease with which diagenesis may occur becomes a function of, among other parameters, plankton productivity and, correspondingly, sedimentation rate. Milholland et al. (1980) have applied this concept to pure carbonate sediments in order to develop a geoacoustic model that accounts for observed physical property variations with depth. Thus, it is possible that the high sedimentation rates not only produced the initial excess pore pressures, but also contributed to a condition of high diagenetic potential, thereby promoting a dissolution and recrystallization process among grains which, in turn, enhanced the rigidity of the open framework.

An additional mechanism that could account for the absence of compaction across various depth intervals at these pertinent sites relates to proper grain size and sorting. Both cementation and mechanical compaction are influenced by these two particle properties. Heald and Renton (1966) have demonstrated that fine sands, with their considerable surface area, are much more susceptible to dissolution effects than are coarser ones. Robertson (1967) has reported laboratory results that illustrate the effects of grain size and rate of loading upon the consolidation of a carbonate sediment. Coogan and Manus (1975) describe a condition known as bridging, whereby large grains form an interlocking network during the initial steps of consolidation and receive the majority of the overburden load. The smaller grains are located between these prominent particles and contribute little to the overall sediment compressibility. This phenomenon produces a stiff matrix early during the consolidation process and is a direct function of grain size distribution. Well-sorted grains make compaction more likely, whereas poorly sorted, fine grains encourage bridging and cementation. Grain size and sorting characteristics should have a primary effect upon the consolidation be- 


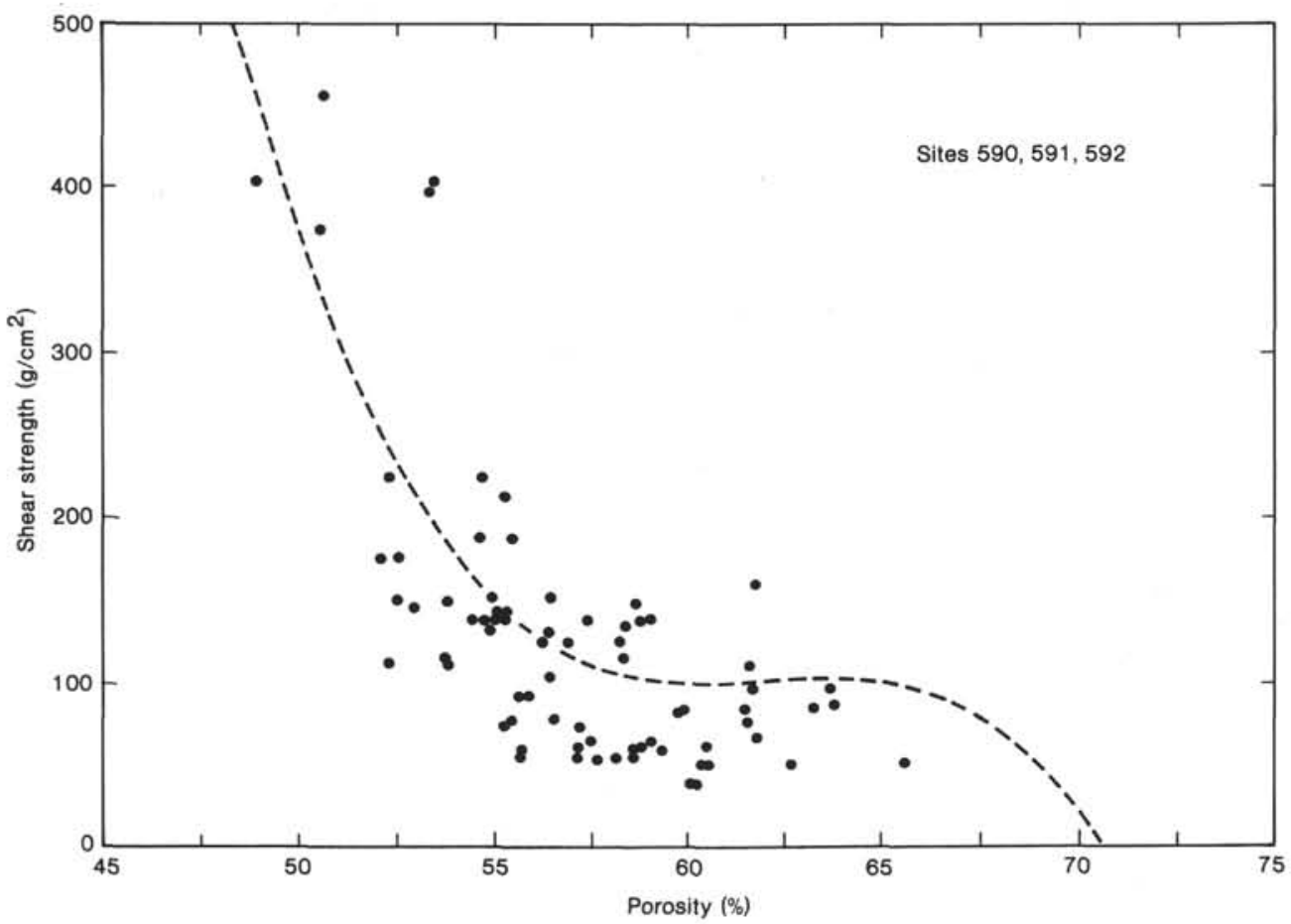

Figure 6. Plot of sediment shear strength versus porosity for three sites. Dashed line represents least-squares polynomial fit.

havior of calcareous ooze and chalk. Grain size distribution analyses on specific Leg 90 samples are currently being conducted at shore-based geotechnical laboratories.

It is hypothesized, therefore, that some combination of the three following factors may have contributed to the unusually constant porosity-versus-depth profiles evidenced at these sites.

1. Excess pore pressures caused by spectacular sedimentation rates retarded initial compaction and promoted the formation of an open sediment microstructure.

2. Excessive sedimentation rates increased the diagenetic potential of the calcareous sediments, thereby accelerating cementation processes among grains and increasing sediment rigidity.

3. Appropriate grain size distributions provided a good mechanical fit among particles and prevented further consolidation from occurring until a threshhold overburden stress finally initiated additional compaction. A small median grain size also encouraged dissolution and reprecipitation.

The ooze-to-chalk transition, whether it was simply the product of mechanical compaction and particle reorientation or brought about through diagenetic alteration, coincides clearly with sharp, substantial increases in shear strength. Variations in compressional velocity at this stage are also present, though the relationship is much less distinct. The thermal conductivity results all fall within the limits established by the Hashin and Shtrikman (1962) model, but a uniform shift in the data from Curve $\mathrm{C}$ to Curve $\mathrm{D}$ with declining porosity is not obvious (Fig. 4). It does not appear, therefore, that the oozeto-chalk transformation affects this property to the extent that it does the shear strength; a transitional porosi- ty range cannot be identified from the plots presented in Figure 4. It is interesting to consider, as a final note, that the porosity range over which the sediment undergoes this major lithological change is very narrow, perhaps only 1 or $2 \%$.

\section{ACKNOWLEDGMENTS}

J. Gardner assisted in collecting the physical properties data throughout the cruise; J. Pine performed all of the carbonate bomb tests. Their help is gratefully appreciated.

\section{REFERENCES}

Baas Becking, L. G. M., and Moore, D., 1959. Density distribution in sediments. J. Sediment. Petrol., 29:45-55.

Bathurst, R. G. C., 1971. Carbonate Sediments and Their Diagenesis: Amsterdam (Elsevier).

Boyce, R. E., 1976a. Deep Sea Drilling Project procedures for shear strength measurements of clayey sediments using modified Wykeham-Farrance Laboratory vane apparatus. In Barker, P. F., Dalziel, I. W. D., et al., Init. Repts. DSDP, 36: Washington (U.S. Govt. Printing Office), 1059-1068.

Boyce, R. E., 1976b. Definitions and laboratory techniques of compression sound velocity parameters and wet-water content, wet-bulk density, and porosity parameters by gravimetric and gamma ray attenuation techniques. In Schlanger, S. O., Jackson, E. D., et al., Init. Repts. DSDP, 33: Washington (U.S. Govt. Printing Office), 931-958.

Chaney, R. C., Ramanjaneya, G., Hencey, G., Kanchanastit, P., and Fang, H. Y., 1983. Suggested test method for determination of thermal conductivity of soil by thermal-needle procedure. Geotech. Testing J., 6:220-225.

Clark, S. P. (Ed.), 1966. Handbook of Physical Constants: Boulder (Geological Society of America).

Coogan, A. H., and Manus, R. W., 1975. Compaction and diagenesis of carbonate sands. In Chilingarian, G. V., and Wolf, K. H., (Ed.), Developments in Sedimentology: Compaction of Coarse-Grained Sediments: Amsterdam (Elsevier), pp. 79-166.

Crane, R. A., and Vachon, R. I., 1977. A prediction of the bounds on the effective thermal conductivity of granular materials. Int. J. Heat Mass Transfer, 20:711-723. 
Hashin, Z., and Shtrikman, S., 1962. A variational approach to the theory of the effective magnetic permeability of multiphase materials. J. Appl. Phys., 33:3125-3131.

Heald, M. T., and Renton, J. J., 1966. Experimental study of sandstone cementation. J. Sediment. Petrol., 36:977-991.

Jeffrey, D. J., 1973. Conduction through a random suspension of spheres. Proc. Roy. Soc. London, 335:355-367.

Mayer, L. A., 1979. Deep sea carbonate: acoustic, physical, and stratigraphic properties. J. Sediment. Petrol., 49:819-836.

1982. Physical properties of sediment recovered on DSDP Leg 68 with the hydraulic piston corer. In Prell, W. L., Gardner, J. V., et al., Init. Repts. DSDP, 68: Washington (U.S. Govt. Printing Office), 365-382.

Milholland, P., Manghnani, M. H., Schlanger, S. O., and Sutton, G. H., 1980. Geoacoustic modeling of deep-sea carbonate sediments. J. Acoust. Soc. Am., 68:1351-1360.

Robertson, E. C., 1967. Laboratory consolidation of carbonate sediment. In Richards, A. F. (Ed.), Marine Geotechnique: Urbana (Univ. of Ill. Press), pp. 118-127.
Schlanger, S. O., 1963. Subsurface geology of Eniwetok Atoll. U.S. Geol. Survey Prof. Paper, 260BB:991-1066.

Schlanger, S. O., and Douglas, R. G., 1974. The pelagic ooze-chalklimestone transition and its implications for marine stratigraphy. Int. Assoc. Sedimentol., Spec. Publ., 1:117-148.

Weller, J. M., 1959. Compaction of sediments. Am. Assoc. Petrol. Geol. Bull., 43:273-310.

Wilkens, R. H., and Langseth, M. G., 1983. Physical properties of sediments of the Costa Rica Rift, Deep Sea Drilling Project Sites 504 and 505. In Cann, J. R., Langseth, M. G., et al., Init. Repts. DSDP, 69: Washington (U.S. Govt. Printing Office), 659-674.

Wyllie, M. R. J., and Southwick, P. F., 1954. An experimental investigation of the s.p. and resistivity phenomena in dirty sands. J. Petrol. Tech., 44-57.

Date of Initial Receipt: 18 June 1984 Date of Acceptance: 26 October 1984
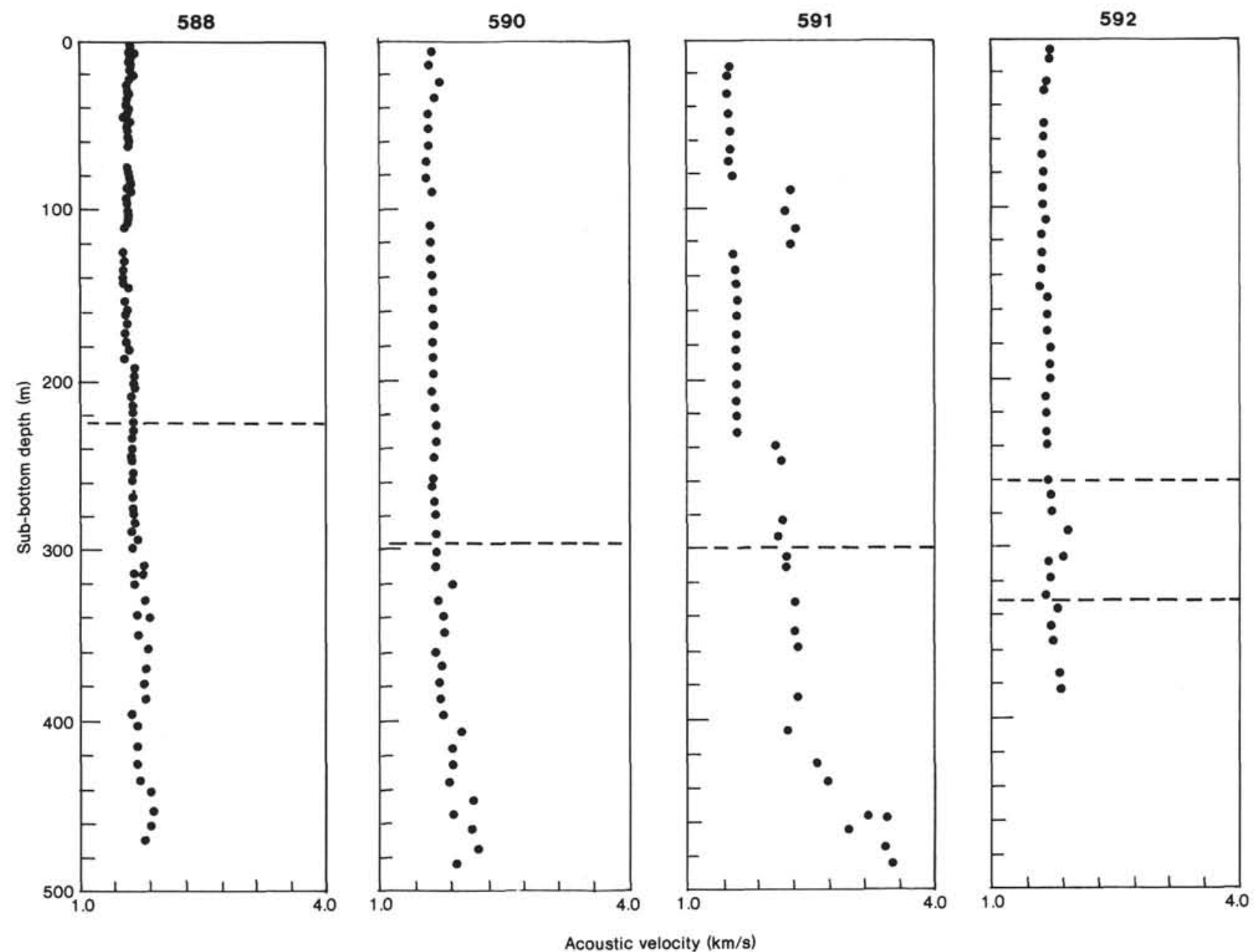

Figure 7. Multiple plot of acoustic compressional velocity versus depth for four sites. Dashed line indicates ooze-to-chalk transitional depth. 